\title{
A rare presentation of flexor digitorum profundus type $V$ avulsion injury with associated intra-articular fracture: A case report
}

\author{
D Rizis MD, JL Mahoney MD FRCSC FACS
}

D Rizis, JL Mahoney. A rare presentation of flexor digitorum profundus type $\mathrm{V}$ avulsion injury with associated intra-articular fracture: A case report. Can J Plast Surg 2011;19(2):62-63.

Traumatic avulsions of the flexor digitorum profundus tendon are associated with young adults engaged in athletic activities such as football and rugby. The current report presents a case involving a 30-year-old man with traumatic avulsion of his flexor digitorum profundus and associated intraarticular distal phalangeal fracture secondary to injury during martial arts an unusual cause of this injury. Increased attention to injuries acquired during this form of sporting activity is suggested.

Key Words: Avulsion fracture; Flexor digitorum profundus; Jersey finger

\section{Une rare présentation d'avulsion de type $\mathrm{V}$ du muscle fléchisseur profond des doigts associée à une fracture intra-articulaire : un rapport de cas}

Les avulsions traumatiques du tendon du muscle fléchisseur profond des doigts s'observent chez les jeunes adultes qui participent à des activités athlétiques comme le football et le rugby. Le présent rapport présente le cas d'un homme de 30 ans ayant une avulsion traumatique du muscle fléchisseur profond des doigts et une fracture intra-articulaire de la phalange distale connexe, consécutives à une blessure subie en pratiquant des arts martiaux, ce qui constitue une cause inhabituelle de ce type de blessure. Il est suggéré d'accorder plus d'attention aux blessures subies pendant la pratique de ce type d'activité sportive.
A vulsions of the flexor digitorum profundus (FDP) tendon are referred to as jersey fingers and most commonly occur in young men involved in athletic activities. They are often seen in football and rugby players, and involve hyperextension of the distal interphalangeal (DIP) joint against contracted flexion force (1). These injuries have been reported to occur in the ring finger in more than $75 \%$ of cases $(2,3)$.

\section{CASE PRESENTATION}

A 30-year-old, right-handed man was referred to a hand clinic due to an injury to his left ring finger at the level of the distal phalangeal area. This injury had occurred several days earlier during a sparring session in his karate class. The patient did not experience any pain or notice the injury at the time of the sparring session. It was only later, in the locker room, that he felt pain at the level of the distal joint. He was initially led to believe that it was a slight sprain and decided not to seek medical attention until two days postinjury, when the pain and swelling had not subsided.

On evaluation, the patient experienced pain over the DIP joint of his left ring finger, which was neurovascularly intact. A painful body eminence was palpable on the volar side of the distal phalanx, and there was no active flexion of the DIP joint. The $\mathrm{x}$-rays revealed a comminuted fracture of the base of the distal phalanx, with displacement of the volar fragment to the approximate level of the A4 pulley (Figure 1). The need for surgery, risks and complications, and convalescence were discussed, and surgery was scheduled two days later.

The distal flexor tendon sheath was exposed using a Bruner incision. The FDP tendon with its associated avulsed bone fragment were located and retrieved at the level of the A4 pulley. This fragment was reduced using a pull-out technique, and a $\mathrm{K}$-wire was placed along the volar side of the avulsed fragment as a buttress to maintain reduction. Proper reduction was confirmed with $\mathrm{x}$-rays (Figure 2), and the patient's hand was placed in a splint.

He was initiated in an immediate range of motion protocol and progressed, achieving excellent range of motion by three months (Figure 3). He experienced no postoperative complications.

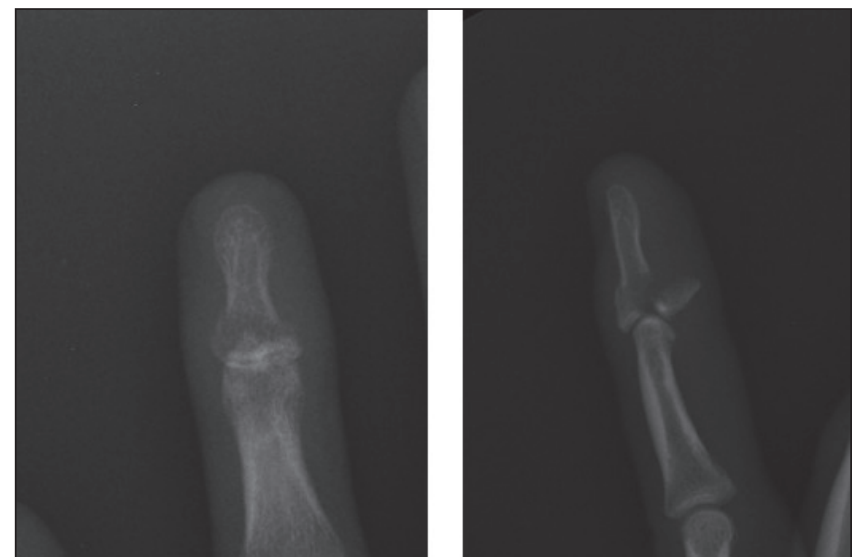

Figure 1) Anterior and lateral plain radiographs of the injury taken in the emergency department

\section{DISCUSSION}

Avulsion injuries were classified into three types by Leddy and Packer (1) in 1977. Modifications to this classification have been made as variations of FDP avulsions have been recognized. There are currently five general types of FDP avulsions; some classifications include subtypes $(4,5)$. In type I avulsions, the FDP is avulsed without fracture and retracts into the palm; the vincula longus and brevis are ruptured. In type II avulsions, the FDP retracts to the level of the proximal interphalangeal joint; the long vinculum usually remains intact. Type III avulsions have large avulsed bony distal fragments that become caught in the A4 pulley preventing further retraction. Both vincula remain intact. Type IV avulsions were first described by Robins and Dobyns (6) in 1974. In 1981, Smith (7) proposed that they be included in the Leddy and Packer classification. Type IV avulsions occur when there is combined bony avulsion and tendon avulsion from the bony fragment, thus creating two injuries. Inclusion of type $\mathrm{V}$ avulsions in the classification was proposed by Al-Qattan (5) in 2001. In this type of avulsion, the bony avulsion of the FDP is coupled 

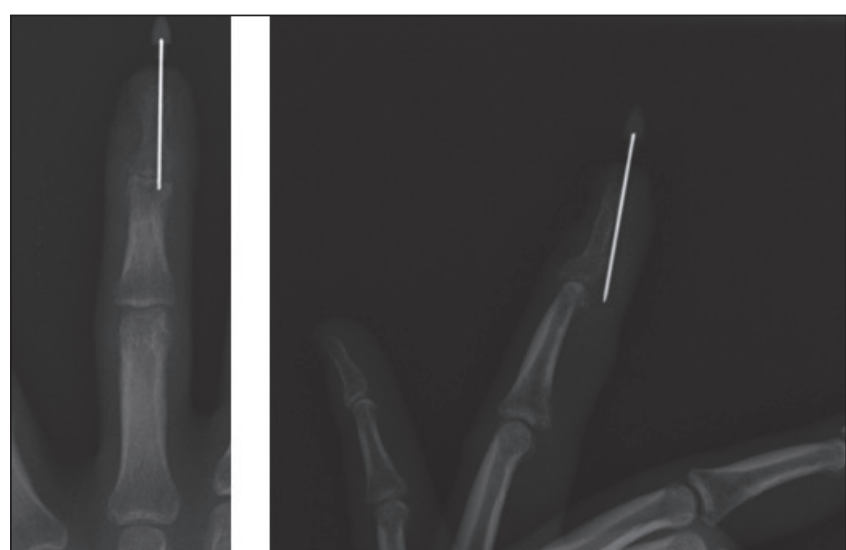

Figure 2) Anterior and lateral plain radiographs of the injury taken postoperatively

to a distal phalanx fracture, with extra-articular or intra-articular $(\mathrm{Vb})$ subtypes.

The relative incidence of each subtype has not been clearly reported in the literature. Type II injuries seem to be most common, as reported by Leddy and Packer (1). Type III injuries follow type II in incidence; types I, IV and V are less common $(2,4,8)$. It was shown that $50 \%$ of FDP tendon avulsions are associated with large bony fragments (9).

Management of these injuries is highly dependent on the classification and can range from a simple pull-out suture to open reduction internal fixation with tendon fixation $(1,4,5)$. In type $\mathrm{Vb}$ injuries, similar to the one described in the present report, stability of the DIP joint should be obtained before fixation of the avulsed osseous fragment. The proposed method is $\mathrm{K}$-wire stabilization of the DIP followed by reduction pull-out suturing of the avulsed fragment tied over a button on the dorsum of the finger. A dorsal blocking splint is suggested with $20^{\circ}$ flexion in both the wrist and metacarpophalangeal joints. The splint and $\mathrm{K}$-wire can be discontinued at four weeks. The pull-out suture is removed at six weeks (5). Prompt management is also suggested, with arthrodesis of the DIP becoming a more likely outcome if treatment is delayed by more than 10 days after the initial injury (4).
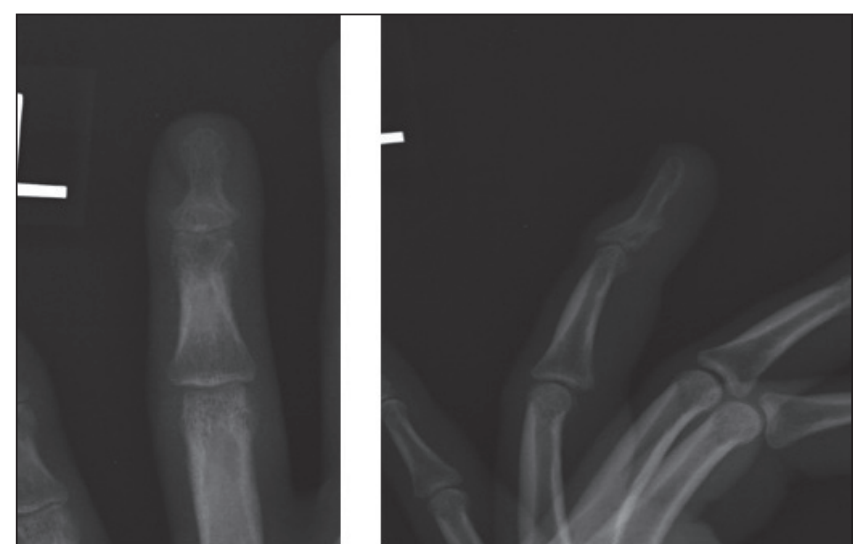

Figure 3) Anterior and lateral plain radiographs of the injury taken at threemonth follow-up

This particular case differs from the typical presentation of FDP avulsions in that the commonly seen forced extension against active flexion is not the mechanism of injury. The patient was practicing karate, a striking type of martial art, when the injury occurred. It has been shown that karate athletes have an annual injury incidence rate of 44.6 injuries per 100 athletes; $28.9 \%$ of these injuries involve the upper limb. Most injuries are minor and involve thumb or finger sprains or forearm hematomas (10). It is assumed that the injury described in the present article would be more commonly associated with grappling martial art types, which involve grasping and pulling. The patient reported no such incident.

Most reports and studies of FDP avulsion involve the typical jersey finger mechanism occurring in football or rugby. Some cases of FDP avulsion injuries secondary to minor trauma with underlying enchondromas have been reported (11-15). However, to our knowledge, no case of type V FDP avulsion secondary to a striking mechanism in a patient without an underlying predisposing condition has been previously reported. The present case involves a novel mechanism of injury for a rare type Vb FDP avulsion. It illustrates the sport's potential to cause serious injury, and emphasizes the need for a thorough evaluation of hand function when examining patients with hand injuries who compete in this sport.

\section{REFERENCES}

1. Leddy JP, Packer JW. Avulsion of the profundus tendon insertion in athletes. J Hand Surg 1977;2A:66-9.

2. Manske PR, Lesker PA. Avulsion of the ring finger flexor digitorum profundus tendon: An experimental study. Hand 1978;10:52-5.

3. Murphy BA, Mass DP. Zone I flexor tendon injuries. Hand Clin 2005;21:167-71.

4. Tuttle HG, Olvey SP, Stern PJ. Tendon avulsion injuries of the distal phalanx. Clin Orthop Relat Res 2006;455:157-68.

5. Al-Qattan MM. Type 5 avulsion of the insertion of the flexor digitorum profundus tendon. J Hand Surg 2001;26B:427-31.

6. Robins PR, Dobyns JH. Avulsion of the insertion of the flexor digitorum profundus tendon associated with fracture of the distal phalanx: A brief review. AAOS 1974:151-6.

7. Smith JH Jr. Avulsion of the profundus tendon with simultaneous intraarticular fracture of the distal phalanx - case report. J Hand Surg 1981;6A:600-1.

8. Moieman NS, Elliot D. Primary flexor tendon repair in zone I. J Hand Surg 2000;25:78-84.

9. Eglseder WA, Russel JM. Type IV flexor digitorum profundus avulsion. J Hand Surg 1990;15:735-9.

10. Destombe C, Lejeune L, Guillodo Y, et al. Incidence and nature of karate injuries. Joint Bone Spine 2006;73:182-8.

11. Yamauchi T, Yoshii T, Sempuku T. Flexor digitorum profundus avulsion of the left little finger through enchondroma of the distal phalanx: Pull-out wire technique treatment without bone graft. Hand Surg 2008;13:17-20.

12. Gollapenne RP, Anwar M, Jacobs L. Flexor digitorum profundus avulsion through an enchondroma of the distal phalanx. J Hand Surg 2007;32:596-7.

13. Chen DB, Tee DC. Flexor digitorum profundus avulsion through a recurrent enchondroma - a case report. Hand Surg 2001;6:125-6.

14. Canovas F, Nicolau F, Bonnel F. Avulsion of the flexor digitorum profundus tendon associated with a chondroma of the distal phalanx. J Hand Surg 1998;23:130-1.

15. Froimson AI, Shall L. Flexor digitorum profundus avulsion through enchondroma. J Hand Surg 1984;9:342-4. 